\title{
Belediyelerde Performans Ölçümü için D-ANP Temelli Bir Kurumsal Performans Kartı Uygulaması \\ Burak ERKAYMAN ${ }^{1}$ \\ Mustafa Engin KOCADAĞísTAN ${ }^{2}$ Özge ALBAYRAK ${ }^{3}$
}

\begin{tabular}{|c|c|}
\hline $\begin{array}{c}\text { Kabul Tarihi/ Accepted } \\
21 / 09 / 2020 \\
\end{array}$ & $\begin{array}{c}\text { Yayın Tarihi/ Published } \\
23 / 10 / 2020 \\
\end{array}$ \\
\hline $\begin{array}{l}\text { Citation/Atıf: Erkayman, B., Kocadağistan M. E. ve Alba } \\
\text { Performans Ölçümü için D-ANP Temelli bir Kurumsal Perforn } \\
\text { Universitesi İktisadi ve İdari Bilimler Dergisi, } \\
\text { https://doi.org/10.16951/atauniiibd.761957 }\end{array}$ & $\begin{array}{l}\text { Ö., (2020), Belediyelerde } \\
\text { Kartı Uygulaması, Atatürk } \\
\text { Sayfa: 1491-1511, DOI: }\end{array}$ \\
\hline
\end{tabular}

Öz: Günümüzde kamu kuruluşlarının çoğu performanslarını iyileştirmeye, insanlara daha iyi hizmet ve daha iyi yaşam kalitesi sunabilmek için hedeflerine ulaşmaya çalışırlar. $\mathrm{Bu}$ kuruluşların çoğu için belli vizyon, misyon ve hedeflerle stratejiler geliştirmek bir norm haline gelmiştir. Kuruluşlara strateji yönetimi ve performans ölçümünde rehberlik edecek çeşitli stratejik çerçeveler bulunmaktadır. Bu çerçevelerden biri olan Dengeli Puan Kartı (BSC) dört boyutu ile bu çalışmada kullanılmışır. Çalışmada kapsamında bir ilimizdeki belediyenin performansını değerlendirmek için kurumsal karneleme boyutları ele alınarak hibrit çok kriterli karar verme yöntemi DEMATEL-ANP (D-ANP) kullanılmıștır. Burada DEMATEL yöntemi kriterler arası ilişkileri dikkate alarak kriter ağırlıklarını belirlemek için kullanılmış ve ANP yöntemiyle birleştirilerek her boyut ve kriter için etkili ağırlıklar hesaplanmıştır. Bu ağırlıklara göre de belediyenin performansı kurumsal karnelemenin dört boyutu açısından değerlendirilmiştir. Elde edilen sonuçlara göre performans değerlendirmesinde en önemli kriterin hizmet sonrası gelen şikâyetlerin azaltılması olduğu bulunmuş ve kurumsal karneleme boyutlarından iç süreçler boyutuna daha fazla önem verildiği görülmüş̧ür.

Anahtar Kelimeler: Cok Kriterli Karar Verme, DEMATEL, ANP, Dengeli Puan Kartı

\section{A D-ANP Based Balanced Score Card Application for Performance Measurement in Municipalities}

Abstract: Most of today's public institutions try to improve their performance and reach their goals in order to provide people with better service and better quality of life. For many of these organizations, developing strategies with specific visions, missions and goals has become a norm. There are several strategic frameworks to guide organizations in strategic management and performance measurement. One of these frameworks, Balanced Scorecard (BSC), was used in this study with its four dimensions. Within the scope of the study, DEMATEL-ANP (D-ANP) was used to evaluate the performance of a municipality in our province, by considering the balanced scorecard dimensions. Here, the DEMATEL method was used to determine the criteria weights

\footnotetext{
${ }^{1}$ Doç. Dr., Atatürk Üniversitesi, Mühendislik Fakültesi, Endüstri Mühendisliği, https://orcid.org/0000-0002-9551-2679

${ }^{2}$ Dr. Öğr. Üyesi, Atatürk Üniversitesi, Mühendislik Fakültesi, Metalurji ve Malzeme Mühendisliği, https://orcid.org/0000-0001-6298-0348

${ }^{3}$ Atatürk Üniversitesi, Mühendislik Fakültesi, https://orcid.org/0000-0001-7798-8799
} 
considering the relationships between the criteria and by combining with the ANP method, effective weights were calculated for each dimension and criterion. According to these weights, the performance of the municipality was evaluated in terms of the four dimensions of balanced scorecard. According to the results obtained, it was found that the most important criterion in the performance evaluation was the reduction of the complaints received after the service and it was observed that more importance was given to internal processes dimension thanbalanced scorecard dimensions

Keywords: Multi Criteria Decision Making, DEMATEL, ANP, Balanced Scorecard

\section{EXTENDED SUMMARY}

\section{Research Problem}

The aim of this study is to apply the balanced scorecard management tool, which is successful in various application areas, to a municipality in our province, to examine the strategic performance management of the organization and to give detailed information to the senior management about the performance of the organization.

\section{Literature Review}

Many applications were made in the literature on corporate performance management and corporate performance management in local governments and different techniques were used. Güner and Memiş (2007), evaluated the development of Corporate Performance evaluation methods in the process. A general analysis for performance management in municipalities was done by Köseoğlu (2005). A study on rethinking performance evaluation methods in local governments has been explained by Demirel (2018) on UK examples. Okutan and Yilmaz (2019) worked as an example of Mersin Metropolitan Municipality on public performance evaluation. Günay and Kaya (2017), the performance of brokerage firms operating in Borsa İstanbul has been evaluated with the support of ELECTRE, ORESTE and TOPSIS methods. Abikova (2020) used DEMATEL-ANP methods together for the selection of the settlements of the refugee camps.

\section{Methodology}

In this study, 51 criteria obtained through a detailed literature review for the four dimensions of balanced scorecard were used in order to establish the strategic performance management of a municipality in our city and to give detailed information about its performance to the senior management. The effects of balanced scorecard dimensions and evaluation criteria on each other were evaluated by a group of experts.

\section{Application}

In this study, multi-criteria decision making methods were used to estimate the main effects on the performance of the municipality. The Hybrid DANP method used in the study is an effective method that can be used to examine the complex relationships between criteria and to obtain the weights of the criteria without further research. First, the DEMATEL method was applied to create the total relationship matrix and to investigate the cause-effect relationships between 
parameters derived from different dimensions and criteria. Then DANP method was used to calculate effective weights. Finally, according to these weights, the performance of the public institution was evaluated in terms of the four dimensions of institutional scorecard.

\section{Results}

According to the results obtained from the DANP method, 0.0302 and C30 for the citizens: reduction of complaints received after service has been determined as the criterion with the highest weight. Based on these results, it was seen that more importance was given to the internal scorecard dimensions than the corporate scorecard dimensions, and the customer dimension followed.

\section{Giriş}

Günümüzde sürekli değişen rekabet şartlarında başarılı olabilmek için iş ile ilgili kararları güvenilir ve hızl bir şekilde almak gerekmektedir. Kurumun performans hedeflerine ulaşma yolunda performansını doğru ölçebilmek ve avantaj getirecek kararları tam zamanında alabilmek için kurum bünyesine icra edilen süreçlere ve bu süreçler içinde üretilen doğru veriye ihtiyaç vardır. Çünkü iş hayatında teknolojinin çok hızlı bir şekilde geliştiği günümüz şartlarında, kurumların gerek bu gelişime ayak uydurmaları gerekse de bu uyum sırasında yaşanan performans ve rekabet ortamları ön plana çıkmaktadır. Dünya düzeni üzerinde kurumsal olarak yaşanan rekabet ortamlarında yönetim ve örgütsel gayretlerin başarı ile sonuçlanabilmesinde temel nokta kurum çalışanları ve bu çalışanların hizmet ettiği insan yani müşteri unsurlarıdır. Kurumların performans değerlendirmeleri, verimliliklerinin artırılması amacına yöneliktir. Özellikle yerel yönetimlerin müșteri odaklı hizmet vermeleri, performans değerlendirmelerini önemli kılmaktadır. Performans değerlendirmelerinde özellikle yapılacak mülakatlar, geçmişe yönelik sicil arşiv araştırmaları incelenmektedir. Kriterler arasında ödüllendirme, ücret ve bu ücretlerin optimum dağılımları ile ileriye yönelik kariyer planlamaları ve verilen eğitimler gibi birçok konu araştırılmaktadır. Yerel yönetimlerde, yıllar bazında değişim gösteren yönetim ve yönetici profili, personel kanunları, personele yaklaşım, hizmet kalitesi, hizmet verilen vatandaş profili gibi kriterlerin göz önüne alınması gerekmektedir. Kurumsal performans yönetimi yerel yönetimler bazında, hızlı kentleşme, sosyalleşme ve teknolojik gelişimlere ayak uydurmayı zorunlu kılmaktadır. Bu kapsamda iş yoğunluğu bakımından performans yönetimine daha fazla ihtiyaç duyulmaktadır. Çağdaşlaşma ve yenilikçilik adına yerel yönetimlerin müşteri odaklı hizmet noktasında, personellerine ön plana çıkarması gerekmektedir. Çünkü hizmet verilen toplumun en üst kesiminden en alt kesimine kadar birçok kişi ile muhatap olunması, sorunlarının çözülmesine çalışılması, hizmeti veren personelin mutlak surette gelişimlere paralel olarak eğitilmesini gerekli kılmaktadır. Bunun için de öncelikle personellerinin verdikleri hizmetlere uygun potansiyellerinin belirlenerek görevlendirilmesi, görevlendirildikleri kesimde bilgili, huzurlu ve mutlu olması, işlerini layığı ile yapıyor olması, 
motivasyon konusunda her türlü desteğin sağlanması şarttır. Bu doğrultuda yapılan işten etkin sonuçlar alınması ve verimliliğin yükseltilmesi beklenmektedir. Performans ölçüm ve değerlendirmeler sonrasında, verilen hizmetlerin geri dönüşlerinin daha iyi olmasına, verilen hizmet kalitesinde artışlara, problemlerin zamanında, tam ve sorunsuz bir şekilde çözümüne, dolayısıyla da vatandaş memnuniyetine ulaşılacaktır. $\mathrm{Bu}$ işlemler sonucunda yapılacak olan anketlerle bu memnuniyetlerin seviyelerinin de ölçülmesi sistemin kontrolü açısından önemli olacaktır. Yerel yönetimlerde verilen hizmetlerin bir standardı olmaması, yani vatandaşın her tür problemde başvuru yapabildiği bir kurum olmasından dolayı verilen bu hizmetlerin mutlak surette başarılı olmasını gerektirmektedir. Bunun yanında uygulanacak ücret politikası, personel becerileri, verdiği hizmet için almış olduğu eğitimler, hizmetlerin gelişimlere paralel olarak sürdürülmesi, kariyer planlamaları ve yönetimi, stratejik planlamalar gibi konularda performans ölçümleri hiç şüphe yok ki, hizmet kalitesinin artırılması noktasında artık bir zorunluluktur. Yerel yönetimlerde görev alan tüm çalışanların hizmet performansı konusunda uzun vadeli ve sürekli gelişimleri amaçlanmalı ve bu amaçlara ulaşım konusunda ihtiyaç duyulan müşteri odaklı hizmette ölçme, kontrol, planlama, yönlendirme, sonuçlandırma gibi konuları bir arada yürütmek gerekmektedir.

$\mathrm{Bu}$ çalışmanın amacı, çeşitli uygulama alanlarında başarılı olan bir yönetim metodolojisi önermek ve değerlendirmektir. Bu amaçla, kurumsal karneleme yönetim aracı bir ilimizdeki belediyeye uygulanmakta olup, kuruluşun stratejik performans yönetimini incelemek ve kuruluşunun performansı hakkında üst yönetime detaylı bilgi vermek amaçlanmıştır.

Çalışmanın giriş bölümünün ardından konuyla ilgili geçmişte yapılan çalışmalar taranmış, ikinci bölümde kurumsal karneleme, hibrit DEMATELANP yöntemleriyle ilgili bilgiler verilmiş, üçüncü bölümde belediyenin performans yönetimiyle ilgili elde edilen bulgulara yer verilmiştir, son bölümde ise sonuçlar ve gelecekteki çalışmalar için önerilerde bulunulmuştur.

\section{Literatür Taraması}

Kurumsal performans yönetimi ve yerel yönetimlerde kurumsal performans yönetimi konularında literatürde birçok uygulama yapılmış ve farklı teknikler kullanılmıştır. $\mathrm{Bu}$ makalede kullanılan performans değerlendirme yöntemi Kaplan ve Norton tarafindan bilim dünyasına kazandırılan Kurumsal Performans Kartı (Balanced Scorecard) yöntemidir. Bu yöntemin Türkçe karşıllğı Kurumsal Karneleme, Kurumsal Performans Karnesi, Dengeli Performans Kartı gibi farklı ifadelerle sunulabilmektedir. Gencer ve Çetin tarafindan havacılık sektöründe bir uygulama gerçekleştirilmiştir. Söz konusu çalışmada AHP (Analitik Hiyerarşi Prosesi) tekniğinden yararlanılmıştır (Gencer $\&$ Çetin, 2011). Güner ve Memiş Kurumsal Performans değerlendirme yöntemlerinin gelişimini süreç içinde değerlendirmiştir (Güner \& Memış, 2007). Belediyelerde performans yönetimi için genel bir analiz Köseoğlu tarafindan 
yapılmıştır (Köseoğlu, 2005). Türk kamu sektöründe performans yönetimine bakış açısını ayrıntılı bir şekilde Karasoy sunmuştur (KARASOY, 2014). Yine Türk Kamu yönetiminde performans denetiminin mümkün olup olmadığına dair bir çalışma Övgün ve arkadaşları tarafından irdelenmiştir (Övgün, Özkal Sayan, \& Zengin, 2018)Yılmaz, kurumsal sürdürülebilirlik ölçümünde kurumsal performans kartı uygulamasını TOPSIS yöntemi kullanarak yapmıştır (Yılmaz, 2018). Performans değerlendirme ve öneri sitemlerinin sürdürülebilir verimliliğe etkisi bir örnek olay çalışması yardımıyla açıklanmıştır (Sarıaltın, 2017). Yerel yönetimlerde performans ölçümü ve karşılaşılan sorunları Akçakaya ayrıntılı bir biçimde yazmıştır (Akçakaya, 2017). Borsa İstanbul'da faaliyet gösteren aracı kurumların performansı ELECTRE, ORESTE ve TOPSIS yöntemleri desteğiyle değerlendirilmiştir (Günay \& Kaya, 2017). Yerel yönetimlerde performans değerlendirme yöntemlerinin yeniden düşünülmesi üzerine bir çalışma Demirel tarafından Birleşik Krallık örnekleri üzerinde açıklanmıştır (Demirel, 2018). Okutan ve Y1lmaz kamuda performans değerlemesi üzerine Mersin Büyükşehir Belediyesi örneği çalışmışlardır (Okutan \& Yılmaz, 2019). Abikova mülteci kamplarının yerleşim yeri seçimi için DEMATEL- ANP yöntemlerini birlikte kullanmıştır (Abikova, 2020). Aynı yöntemin bir başka hibrit şekli yeşil bina derecelendirme problem için uygulanmıştır (Liu, Lo, \& Liou, 2020). Benzer şekilde sürdürülebilir gıda imalatının stratejik haritalaması için TOPSİS yöntemiyle birlikte kullanılmıştır (Ocampo, Deiparine, \& Go, 2020). Bununla birlikte sürdürülebilir kalite değerlendirmesi için de söz konusu yöntemlerin düz ve bulanık şekillerine başvurulmuştur (Puente, Fernandez, Gomez, \& Priore, 2020). Organizasyonel gelişim için stratejik kaynaklarla operasyonel araçlar arasındaki uyum için anahtar sinerjiler kurumsal performans kartı yardımıyla yapılmıştır (St-Hilaire, 2020). Kurumsal performans kartı endüstri 4.0 çağında tedarik zincirlerinin performansını değerlendirmek için de kullanılmıştır (Frederico, Garza-Reyes, Kumar, \& Kumar, 2020). Tayland'da toplum hastanelerinin ve devlet okullarının performansının ölçülmesinde yine kurumsal karneleme yöntemine başvurulmuştur (Aujirapongpan, Meesook, Theinsathid, \& Maneechot, 2020).

\subsection{Kurumsal Karneleme}

\section{Metodoloji}

Kurumsal karneleme ilk olarak 1992 yılında özel sektördeki kuruluşların yönetim ve performans değerlendirme sorunlarını çözmek için Kaplan ve Norton tarafindan oluşturulmuştur. Örgütün gelişimi ve izlenmesi için diğer önemli gerçekleri sağlayabilecek geleneksel finansal ölçütlerin yanı sıra finansal olmayan ölçütler de tamamlayıcı olarak görülmüştür (R. Kaplan \& Norton). Kurumsal karneleme, firmaların misyon ve stratejilerini anlaşılabilir performans ölçümlerine dönüştürerek stratejik performans yönetimi için bir çerçeve oluşturan ve üst yönetime firmanın performansı hakkında geniş bir bakış açısı sağlayan stratejik bir performans değerlendirme yöntemidir (ERBAŞI). Kapsamlı 
bir yaklaşım olan BSC, kuruluşların stratejik yönetim sistemini uygulamalarına yardımc1 olur.

Kaplan ve Norton'un BSC felsefesi, bir kurumun stratejisini dört boyutta değerlendirir. Bunlar; Finansal Boyut, Müşteri Boyutu, İç süreçler Boyutu, Öğrenme ve Gelişim Boyutudur. Bu dört boyutun sebep-sonuç ilişkileri vardır. $\mathrm{Bu}$, müşteri memnuniyetini, yenilikçi ürünleri, yeni teknolojiyi ve çalışan eğitimini iyileştirmenin finansal performansı etkileyebileceği anlamına gelir. BSC, geleneksel finansal endekslerden dengeli bir yapıya (finansal ve finansal olmayan, kısa vadeli ve uzun vadeli hedefler) geçen çok boyutlu bir yöntemdir (R. S. Kaplan \& Norton, 1996). Kurumsal karnelemenin boyutları Şekil 1'de gösterilmiştir.

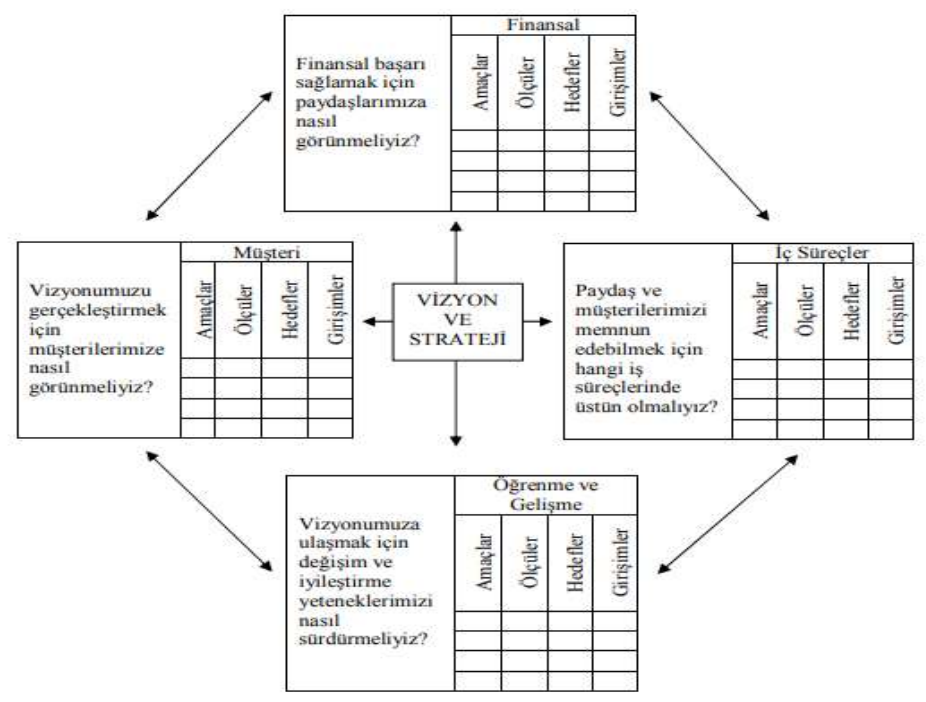

Kaynak:(R. S. Kaplan \& Norton, 1996)

Şekil 1. Kurumsal Karneleme Boyutları

\section{Finansal Boyut}

Finansal boyut, firmanın karlılığı ile ilgili bir unsurdur. Finansal unsurları ölçmek için faaliyet geliri, satış büyümesi, yatırım getirisi vb. kullanılmaktadır. $\mathrm{Bu}$ husus sadece geçmişte şirketin durumunu gösterirken, kurumsal karneleme geçmiş ve ileriye dönük stratejik bir plandır. Dengeli puan kartındaki her ölçüm, sebep-sonuç ilişkisinin bir parçasıdır ve finansal amaçlarla sona ermektedir. Diğer üç yönün etkinliğini ortaya koyar. Pek çok firmada, risk azaltma, verimlilik, artış geliri gibi finansal konular dört unsur arasındaki temel bağlantıyla ortaya çıkabilir (Sarraf \& Nejad, 2020).

\section{Müşteri Boyutu}

Müşteri boyutu, müşterileri hedeflemek ve pazar payı ile ilgili önlemleri dikkate alır. Yöneticiler bu iki unsuru tanımalıdır. Hedef müşterilere ihtiyaçları ve beklentileri doğrultusunda stratejiler oluşturmalarını sağlar. Sonuç 
ölçütlerinden bazıları pazar payı, müş̧eri memnuniyeti, elde tutma, satın alma ve karlılıktır (Agrawal, Singh, \& Murtaza, 2016). Böyle bir yaklaşımın sonuçları, bir kuruluşun operasyonel faaliyetlerini, lojistik, ürün geliştirme ve hizmetleri, dağıtım ve pazarlamanın da dahil olduğu tüm değer zincirini etkiler.

3. İç Süreçler Boyutu

İç süreçler boyutu, bir dizi gelişmiş faaliyet ve eylemleri temsil eder. Müşteri beklentilerini ve taleplerini karşılamak için operasyonel faaliyetlerle ilgilenir. Bunlar kısa vadeli ve uzun vadeli hedefleri içerebilir. Kuruluşlar, müşteriler ve hissedarların memnuniyeti üzerinde büyük etkisi olan iç süreçleri belirlemelidir. Seçilen iç süreçler genellikle müş̧eri boyutunda seçilen hedeflerden ve göstergelerden elde edilir ve müşteri için değer yaratanları belirlenir. Ayrıca teknoloji kullanımı ve atık azaltma, verimlilik, satış sonrası hizmetler ve yenilik, mevcut ve gelecekteki ihtiyaçların korunmasında değer zinciri faaliyetlerinin de bir parçasıdır.

\section{1. Ögrenme ve Gelişim Boyutu}

Öğrenme ve gelişim boyutu, en uygun performans faktörüdür. Kültür ve personel becerilerine odaklanır. Organizasyon performansını artırmak için yöneticiler çalı̧̧anların yeteneklerini geliştirmekten sorumludur (Agrawal et al., 2016). Bu boyut organizasyonda değer yaratmada, bir dizi maddi olmayan değer, özellikle beşeri sermaye, bilgi ve yönetim sistemleri ve organizasyon prosedürlerini içerir.

\subsection{Verilerin Toplanmast}

$\mathrm{Bu}$ çalışmada bir ilimizdeki belediyenin stratejik performans yönetimini oluşturmak ve performansı hakkında üst yönetime detaylı bilgi vermek amaçlanmıştır. Bu amaçla çalışmada kurumsal karnelemenin dört boyutu için detaylı bir literatür taramasıyla elde edilen 51 kriter kullanılmıştır. Çalışmada kullanılan kurumsal karneleme boyutları ve kriterleri Şekil 2'de verilmiştir. Kurumsal karneleme boyutlarının ve değerlendirme kriterlerinin birbirleri üzerindeki etkileri uzman bir grup tarafından değerlendirilmiştir. 
Belediyelerde Performans Ölçümü için D-ANP Temelli Bir Kurumsal Performans Kartı Uygulamast

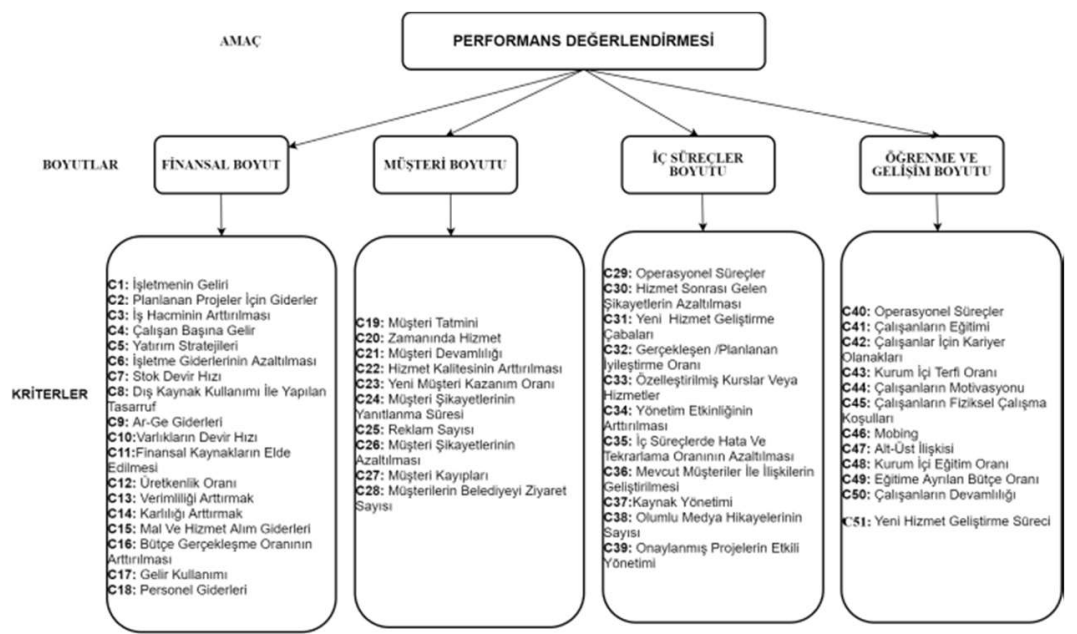

Şekil 2. Belediyenin Performans Değerlendirmesi Iç̧in İncelenen Kriterler

\subsection{DEMATEL Yöntemi}

DEMATEL yöntemi, Cenevre Battelle Memorial Enstitüsü Bilim ve İnsan İlişkileri programı tarafından 1972 ve 1976 yılları arasında geliştirilmiştir. Bu yöntem karmaşı problem grupları arasındaki etkileşimi araştırmak ve analiz etmek için kullanılmıştır (Tzeng, Chiang, \& Li, 2007). DEMATEL yöntemi, karmaşık ve birbirine girmiş yapıdaki bir probleme neden olan kriterlerin hangilerinin etkilenen hangilerinin etkileyen kriterler olduğunun belirlenmesi ile problemi taslak olarak çözme ve analiz etme imkanı sağlar (ALBAYRAK \& ERKAYMAN, 2018).

DEMATEL yönteminin adımları aşağıdaki gibidir: (Aksakal \& Dağdeviren, 2010; Albayrak \& Erkayman, 2018; Wang \& Tzeng, 2012)

Adım 1: Direk ilişki matrisinin oluşturulması

Karar vericilerin kriterleri arasındaki ilişkilerin düzeylerini belirleyebilmeleri için oluşturulan uzman gruptaki her bir uzman tarafindan Tablo 1'de verilen ikili karşılaştırma skalası kullanılarak direk ilişki matrisi (A) elde edilir.

Tablo 1. İkili Karşılaştırma Skalası

\begin{tabular}{cc} 
Sayısal Değer & Tanım \\
\hline 0 & Etkisiz \\
1 & Düşük etki \\
2 & Orta etki \\
3 & Yüksek etki \\
4 & Çok yüksek etki \\
\hline
\end{tabular}


Adım 2: Normalleştirilmiş direk ilişki matrisinin oluşturulması

Bu adımda direkt-ilişki matrisi (A)'a bağlı olarak eşitlik 1 ve 2 kullanılarak normalleştirilmiş direkt ilişki matrisi (M) elde edilir. Bu matrisin esas köşegen değerleri 0'dır.

$$
\begin{aligned}
& \mathrm{M}=\mathrm{r} \times \mathrm{A} \\
& \mathrm{r}=\min \left[\frac{1}{\max \sum_{j=1}^{n}\left|a_{i j}\right|}, \frac{1}{\max \sum_{j=1}^{n}\left|a_{i j}\right|}\right] \quad \mathrm{i}, \mathrm{j} \in\{1,2, \ldots . \mathrm{n}\}
\end{aligned}
$$

Adım 3:Toplam ilişki matrisinin elde edilmesi

Normalleştirilmiş direk ilişki matrisi elde edildikten sonra 3 numaralı eşitlik yardımıyla toplam ilişki matrisi (T) elde edilir. Bu eşitlikte birim matris (I) ile gösterilmektedir.

$$
\begin{aligned}
& \mathrm{T}=\mathrm{M}+M^{2}+M^{3}+\ldots=\sum_{i=1}^{\infty \leftarrow} M^{i} \\
& =M(I-M)^{-1}
\end{aligned}
$$

Adım 4: Gönderici ve alıcı grupların hesaplanması

Toplam ilişki matrisi ( $\mathrm{T}$ ) elde edildikten sonra, matristeki sütun elemanlarının toplamı $\mathrm{R}$ değerini, matristeki satır elemanlarının toplamı ise $\mathrm{D}$ değerini vermek üzere $D+R$ ve D-R değerleri eşitlik 4,5 ve 6 kullanılarak hesaplanir.

$$
\begin{aligned}
& \mathrm{T}=\left[t_{i j}\right]_{n \times n}, \quad \mathrm{i}, \mathrm{j}=1,2, \ldots, \mathrm{n} \\
& \mathrm{D}=\sum_{j=1}^{n} t_{i j} \\
& \mathrm{R}=\sum_{j=1}^{n} t_{i j}
\end{aligned}
$$

Elde edilen $\mathrm{D}+\mathrm{R}$ ve $\mathrm{D}-\mathrm{R}$ değerleri kullanılarak, her bir kriterin diğer kriterlerle aralarındaki etki ve ilişki seviyesi belirlenir. D-R değeri için bazı kriterler pozitif değere sahiptir. Bu kriterlerin diğer kriterler üzerinde daha yüksek etki ve önceliğe sahiptir. Bu tip kriterler etkileyen kriter olarak adlandırılır. D-R değeri için bazı kriterler de negatif değere sahiptir. Bu tip kriterler ise diğer kriterler üzerinde daha düşük etki ve önceliğge sahiptirler ve etkilenen kriter olarak tanımlanırlar.

$\mathrm{D}+\mathrm{R}$ değerleri ise kriterler arasındaki ilişkinin düzeyini göstermektedir. $\mathrm{D}+\mathrm{R}$ değeri yüksek olan kriterler diğer kriterler ile daha çok ilişkilidir. $\mathrm{D}+\mathrm{R}$ değeri düşük olan kriterlerin ise, diğer kriterler ile daha az ilişkili olduğu anlaşılır.

DEMATEL yönteminde kriterler arasındaki ilişkileri bir düzlem üzerinde ortaya koyan etki-yönlü graf diyagramı oluşturulur. Bu diyagramı elde etmek için karar vericilerin etki seviyesi için bir eşik değeri ayarlamaları gerekir. Bu eşik değeri genellikle uzman grup tarafından belirlenir. Etki-yönlü graf diyagramının, yatay ekseninde $D+R$ değerleri, düşey ekseninde ise $D-R$ değerleri yer almaktadır. Toplam ilişki matrisinde eşik değerin üzerinde kalan etkilerin değerleri dikkate alınarak diyagram oluşturulur.

3.4.Kriter Ăğılıklarını Bulmak İçin DEMATEL ve ANP'yi Birleştirmek 
ANP yöntemi, Thomas L. Saaty tarafından geliştirilen karar verme sürecinde etkili olan kriterleri, kriterler arasındaki ilişkileri ve bu ilişkilerin yönlerini hiyerarşik bir ağ şeklindeki model ile ifade eden çok kriterli karar verme yaklaşımıdır (Saaty \& Vargas, 2006). ANP yöntemi, gruplar arası ve grup içi bağımlılıkların yanı sira kriterler arasındaki geri bildirimleri dikkate alması dolayısıyla karar verme problemlerine gerçekçi çözümler sağlamaktadır (Dağdeviren \& Yüksel, 2007).

ANP yönteminde, tüm ikili karşılaştırmaların yer aldığ1 süpermatris oluşturulur ve bu süpermatris sütun toplamları 1 olacak şekilde ağırlıklandırılır. Ancak bu şekilde yapılan ağırlıklandırma kriterler arasındaki etki derecelerinin farkl1 olması nedeniyle, süpermatrisi irrasyonel hale getirebilmektedir. $\mathrm{Bu}$ nedenle, çalışmada bu kriterlerin etki derecelerini belirlemek için DEMATEL tekniği seçilmiş ve ANP yöntemindeki süpermatris oluşturulmuş ve iki yöntemin bütünleştirilmesi sağlanmıştır (Gök \& Perçin, 2016).

$\mathrm{Bu}$ gelişmiş ANP yöntemi D-ANP olarak adlandırıldı ve bu yaklaşımının ANP adımları aşağıdaki gibidir (Gök \& Perçin, 2016; Wang \& Tzeng, 2012; (Hsu, Wang, \& Tzeng, 2012).

Adım 1: Ağırlıklandırılmamış Süpermatrisin Oluşturulması

DEMATEL yönteminden elde edilen toplam ilişki matrisindeki her boyut altında bulunan kriterlerin kendi içlerindeki satır toplamları hesaplanır ve matristeki her değer kendi grubundaki satır toplamına bölünerek normalizasyon işlemi gerçekleştirilir. Normalize edilen bu matrisin transpozesi (devriği) elde edilerek ağırlıklandırılmamış süpermatris (W) elde edilir.

Adım 2: Ağırlıklandırılmış Süpermatrisin Elde Edilmesi

Ağırlıklandırılmamış süpermatrisinin (W) ağırlıklandırılması amacıyla karar probleminin ana boyutları için DEMATEL yönteminden elde edilmiş olan toplam ilişki matrisini kullanılır. $\mathrm{Bu}$ matrisin normalizasyon işlemi gerçekleştirerek hesaplanan veriler yardımıyla, W matrisindeki her kriter ait olduğu boyutun ağırlığı ile çarpılarak ağırlıklandırma işlemi yapılır.

Adım 3: Limit Süpermatrisin Hesaplanmas1

Limit süpermatris, kriterlerin birbirleri üzerindeki uzun dönemli etkilerinin ölçülmesi için, ağırlıklandırılmış süpermatrisin belli bir sayıda kuvvetinin (n) alınması ile oluşturulur. Bu nedenle, ağırlıklandırılmış süpermatrisin her satırı belli bir değerde sabit kalana kadar kendisi ile çarpılır. [ $\lim _{g \rightarrow \infty}\left(W^{a}\right)^{h}$ ]

\section{Uygulama}

$\mathrm{Bu}$ çalışmada çok kriterli karar verme yöntemleri kamu kuruluşunun performansı üzerindeki temel etkileri tahmin etmek için kullanılmıştır. Çalışmada kullanılan Hibrid DANP modeli analitik yöntemleri sadece seçim ve sıralama için değil, aynı zamanda farklı bakış açıları ve performans kriterleri arasındaki boşlukları aydınlatmak için de kullanılmıştır. DANP yöntemi, kriterler arasındaki karmaşı ilişkileri incelemek ve daha fazla araştırma yapmadan kriterlerin ağırlıklarını elde etmek için kullanılabilecek etkili bir yöntemdir. DEMATEL 
sonuçları ve ANP kavramları, orijinal ANP yönteminde olduğu gibi daha fazla çift karşılaştırmaya gerek kalmadan bu etkili ağırlıkları elde etmek için uygulanır (Lu, Hsu, Liou, \& Lo, 2018). Öncelikle DEMATEL yöntemi, toplam ilişki matrisini oluşturmak ve farklı boyut ve kriterlerden türetilen parametreler arasındaki neden-sonuç ilişkilerini araştırmak için uygulanmıştır. Daha sonra etkili ağırlıkları hesaplamak için DANP yöntemi kullanılmıştır. Bu yöntemde DEMATEL yöntemiyle elde edilen toplam ilişki matrisi ANP yöntemiyle birleştirilerek her boyut ve kriter için etkili ağırlıklar hesaplanmıştır. Son olarak, bu ağırlıklara göre kamu kuruluşunun performansı kurumsal karnelemenin dört boyutu açısından değerlendirilmiştir.

\subsection{DEMATEL Yöntemiyle Kriter Ağırlıklarının Belirlenmesi}

Kurumsal karneleme boyutlarının ve değerlendirme kriterlerinin birbirleri üzerindeki etkileri uzman bir grup tarafından değerlendirilmiştir. Uzman grup değerlendirmesi sonucunda kriterler için verilen cevaplara göre oluşturulan 51x51 boyutlu direkt ilişki matrisi Tablo 2'de verilmiştir.

Daha sonra (1) ve (2) no'lu eşitlikler kullanılarak normalize edilmiş direk ilişki matrisi elde edilir. Normalleştirilmiş direk ilişki matrisi elde edildikten sonra eşitlik (3) kullanılarak toplam ilişki matrisi (T) elde edilir ve Tablo 3'de verilmiştir.

Yapılan işlemler kurumsal karnelemenin 4 boyutu için de aynı şekilde tekrarlanarak $4 \times 4$ boyutunda Tablo 4 ile gösterilen direkt ilişki matrisi ve Tablo 5'de gösterilen toplam ilişki matrisi elde edilmiştir.

Tablo 4. Kurumsal Karnelemenin Boyutları İçin Direkt İlişki Matrisinin Oluşturulması

\begin{tabular}{|l|cccc|}
\hline Kriterler & $\begin{array}{c}\text { Finansal } \\
\text { Boyut }\end{array}$ & $\begin{array}{c}\text { Müşteri } \\
\text { Boyutu }\end{array}$ & $\begin{array}{c}\text { İç Süreçler } \\
\text { Boyutu }\end{array}$ & $\begin{array}{c}\text { Öğrenme ve } \\
\text { Gelişim Boyutu }\end{array}$ \\
\hline Finansal Boyut & 0 & 4 & 2 & 1 \\
Müşteri Boyutu & 3 & 0 & 3 & 3 \\
İç Süreçler Boyutu & 2 & 3 & 0 & 2 \\
Öğrenme ve Gelişim Boyutu & 1 & 3 & 3 & 0 \\
\hline
\end{tabular}

Tablo 5. Kurumsal Karnelemenin Boyutları için Toplam İlişki Matrisinin Oluşturulması

\begin{tabular}{|c|cccc|}
\hline Kriterler & $\begin{array}{c}\text { Finansal } \\
\text { Boyut }\end{array}$ & $\begin{array}{c}\text { Müşteri } \\
\text { Boyutu }\end{array}$ & $\begin{array}{c}\text { İç Süreçler } \\
\text { Boyutu }\end{array}$ & $\begin{array}{c}\text { Öğrenme ve } \\
\text { Gelişim Boyutu }\end{array}$ \\
\hline Finansal Boyut & 0.540 & 1.049 & 0.812 & 0.631 \\
Müşteri Boyutu & 0.853 & 0.896 & 0.995 & 0.853 \\
İç Süreçler Boyutu & 0.687 & 0.972 & 0.635 & 0.687 \\
Öğrenme ve Gelişim Boyutu & 0.616 & 0.965 & 0.870 & 0.525 \\
\hline
\end{tabular}

4.2.DEMATEL ve ANP Yöntemleri ile Kriterlerin Ağırlıklandırılması

DEMATEL yönteminden toplam ilişki matrisi verileri elde edildikten sonra çalışmanın ANP adımları izlenerek Ağırlıklandırılmamış Süpermatris (W) elde edilmiştir ve Tablo 6'da verilmiştir. Daha sonra süpermatrisin 
ağırlıklandırılması amacıyla, DEMATEL yönteminde kurumsal karneleme boyutları için oluşturulan toplam ilişki matrisindeki değerler kullanılarak normalizasyon işlemi gerçekleştirilip ağırlıklar elde edilmiştir. Kurumsal karneleme boyutları için hesaplanan ağırlıklar Tablo 7'de gösterilmiştir.

Tablo 7. Kurumsal Karnelemenin Boyutları Iç̧in Ağırlıkların Hesaplanması

\begin{tabular}{|c|cccc|}
\hline Kriterler & $\begin{array}{c}\text { Finansal } \\
\text { Boyut }\end{array}$ & $\begin{array}{c}\text { Müşteri } \\
\text { Boyutu }\end{array}$ & $\begin{array}{c}\text { İç Süreçler } \\
\text { Boyutu }\end{array}$ & $\begin{array}{c}\text { Öğrenme ve } \\
\text { Gelişim Boyutu }\end{array}$ \\
\hline Finansal Boyut & 0.178 & 0.346 & 0.268 & 0.208 \\
Müşteri Boyutu & 0.237 & 0.249 & 0.277 & 0.237 \\
İç Süreçler Boyutu & 0.231 & 0.326 & 0.213 & 0.231 \\
Öğrenme ve Gelişim Boyutu & 0.207 & 0.324 & 0.292 & 0.176 \\
\hline
\end{tabular}

$\mathrm{Bu}$ işlemlerin ardından ağırlıklandırılmamış süpermatrisde (W) her kriter ait olduğu boyutun ağırlığı ile çarpılarak ağırlıklandırılmış süpermatris elde edilmiştir ve Tablo 8'de gösterilmiştir. Son olarak limit süpermatris ise Tablo 9'da verilmiştir. Bu matristeki her satır değeri belediyenin performans ölçümü için elde edilen ağırlıkları temsil etmektedir. Bu sonuçlara göre 0,0302 ile C30: hizmet sonrası gelen şikâyetlerin azaltılması en yüksek ağırlığa sahip kriter olarak belirlenmiştir. $\mathrm{Bu}$ sonuçlara dayanarak kurumsal karneleme boyutlarından iç süreçler boyutuna daha fazla önem verildiği görülmüştür. 
Burak ERKAYMAN - Mustafa Engin KOCADA ĞISTAN - Özge ALBAYRAK

Tablo 2. Direk İlişsi Matrisinin Oluşturulması

\begin{tabular}{|c|c|c|c|c|c|c|c|c|c|c|c|c|c|c|c|c|c|c|c|c|c|c|c|c|c|}
\hline \multirow{8}{*}{ 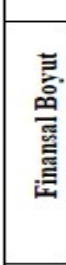 } & Kriterler & Cl & C2 & \begin{tabular}{|l|}
$\mathrm{C3}$ \\
\end{tabular} & $\cdots$ & C16 & C17 & C18 & C19 & $\mathrm{C20}$ & $\mathrm{C} 21$ & $\cdots$ & $\begin{array}{ll}\mathrm{C} 26 \\
\end{array}$ & C27 & $\mathrm{C} 28$ & \begin{tabular}{|l|l|}
$C 29$ \\
\end{tabular} & C.30 & $\cdots$ & \begin{tabular}{|l|} 
C38 \\
\end{tabular} & \begin{tabular}{|l} 
C39 \\
\end{tabular} & \begin{tabular}{|l|l|}
$\mathbf{C 4 0}$ \\
\end{tabular} & \begin{tabular}{|l|}
$\mathrm{C} 41$ \\
\end{tabular} & $\cdots$ & \begin{tabular}{|l|}
$\mathrm{C50}$ \\
\end{tabular} & C51 \\
\hline & $\mathrm{Cl}$ & 0 & 2 & 4 & $\cdots$ & 1 & 4 & 2 & 3 & 2 & 3 & $\ldots$ & 3 & 4 & 2 & 3 & 4 & $\cdots$ & 0 & 3 & 2 & 3 & $\ldots$ & 4 & 3 \\
\hline & $\mathrm{C}_{2}$ & 3 & 0 & 4 & $\ldots$ & 3 & 3 & 2 & 0 & 1 & 4 & $\ldots$ & 3 & 3 & 1 & 3 & 3 & $\ldots$ & 3 & 3 & 2 & 2 & $\ldots$ & 4 & 3 \\
\hline & C3 & 3 & 3 & 0 & $\cdots$ & 2 & 3 & 3 & 2 & 3 & 3 & $\cdots$ & 3 & 3 & 2 & 3 & 2 & $\cdots$ & 2 & 4 & 3 & 2 & $\ldots$ & 1 & 3 \\
\hline & $\vdots$ & $\vdots$ & $\vdots$ & $\vdots$ & $\because$ & $\vdots$ & $\vdots$ & $\vdots$ & $\vdots$ & $\vdots$ & $\vdots$ & $\vdots$ & $\vdots$ & $\vdots$ & $\vdots$ & $\vdots$ & $\vdots$ & $\vdots$ & $\vdots$ & $\vdots$ & $\vdots$ & $\vdots$ & $\vdots$ & $\vdots$ & $\vdots$ \\
\hline & C16 & 2 & 3 & 4 & $\ldots$ & 0 & 4 & 2 & 2 & 2 & 3 & $\ldots$ & 1 & 3 & 1 & 2 & 1 & $\cdots$ & 0 & 4 & 2 & 3 & $\ldots$ & 3 & 1 \\
\hline & $\mathrm{C} 17$ & 2 & 3 & 2 & $\cdots$ & 3 & 0 & 1 & 2 & 2 & 1 & $\ldots$ & 1 & 3 & 1 & 3 & 1 & $\cdots$ & 1 & 3 & 1 & 3 & $\ldots$ & 3 & 3 \\
\hline & C18 & 3 & 1 & 4 & $\ldots$ & 2 & 2 & 0 & 0 & 1 & 1 & $\ldots$ & 2 & 3 & 2 & 3 & 2 & $\ldots$ & 1 & 2 & 3 & 3 & $\ldots$ & 3 & 4 \\
\hline \multirow{7}{*}{ 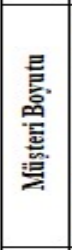 } & C19 & 4 & 2 & 1 & $\ldots$ & 2 & 2 & 0 & 0 & 4 & 4 & $\ldots$ & 3 & 3 & 4 & 2 & 4 & $\cdots$ & 3 & 3 & 3 & 4 & $\ldots$ & 4 & 4 \\
\hline & $\mathrm{C} 20$ & 1 & 1 & 4 & $\ldots$ & 3 & 2 & 2 & 4 & 0 & 4 & $\ldots$ & 4 & 4 & 3 & 4 & 3 & $\ldots$ & 4 & 3 & 3 & 4 & $\ldots$ & 3 & 4 \\
\hline & $\mathrm{C} 21$ & 2 & 3 & 3 & $\cdots$ & 2 & 3 & 2 & 4 & 4 & 0 & $\cdots$ & 3 & 4 & 4 & 4 & 4 & $\cdots$ & 4 & 3 & 4 & 4 & $\ldots$ & 4 & 4 \\
\hline & $\vdots$ & : & $\vdots$ & $\vdots$ & & $\vdots$ & $\vdots$ & $\vdots$ & $\vdots$ & $\vdots$ & $\vdots$ & $\because$ & : & : & : & $\vdots$ & $\vdots$ & $\vdots$ & $\vdots$ & $\vdots$ & : & $\vdots$ & $\vdots$ & : & $\vdots$ \\
\hline & C26 & 2 & 1 & 1 & $\ldots$ & 2 & 2 & 3 & 3 & 4 & 4 & $\ldots$ & 0 & 4 & 4 & 3 & 4 & $\cdots$ & 2 & 2 & 2 & 2 & $\ldots$ & 4 & 3 \\
\hline & $\mathrm{C}_{27}$ & 4 & 2 & 2 & $\ldots$ & 2 & 3 & 3 & 3 & 0 & 4 & $\ldots$ & 3 & 0 & 2 & 4 & 4 & $\ldots$ & 3 & 2 & 4 & 4 & $\ldots$ & 4 & 4 \\
\hline & $\mathrm{C}_{28}$ & 1 & 2 & 4 & $\ldots$ & 0 & 1 & 0 & 4 & 4 & 4 & $\ldots$ & 4 & 3 & 0 & 3 & 3 & $\ldots$ & 4 & 3 & 4 & 4 & $\ldots$ & 4 & 4 \\
\hline \multirow{5}{*}{ 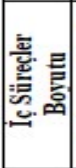 } & C29 & 2 & 3 & 2 & $\cdots$ & 3 & 3 & 3 & 2 & 3 & 3 & $\cdots$ & 4 & 2 & 4 & 0 & 3 & $\cdots$ & 3 & 3 & 2 & 4 & $\cdots$ & 3 & 4 \\
\hline & C30 & 2 & 3 & 1 & $\ldots$ & 1 & 3 & 3 & 3 & 3 & 3 & $\ldots$ & 4 & 2 & 4 & 4 & 0 & $\ldots$ & 2 & 2 & 3 & 4 & $\ldots$ & 4 & 4 \\
\hline & $\vdots$ & $\vdots$ & $\vdots$ & $\vdots$ & $\vdots$ & : & $\vdots$ & $\vdots$ & $\vdots$ & $\vdots$ & $\vdots$ & $\vdots$ & $\vdots$ & $\vdots$ & $\vdots$ & $\vdots$ & $\vdots$ & $\because$ & $\vdots$ & $\vdots$ & $\vdots$ & $\vdots$ & $\vdots$ & $\vdots$ & $\vdots$ \\
\hline & C38 & 3 & 2 & 2 & $\ldots$ & 1 & 3 & 2 & 3 & 3 & 3 & $\ldots$ & 4 & 4 & 4 & 3 & 4 & $\ldots$ & 0 & 3 & 1 & 2 & $\ldots$ & 3 & 4 \\
\hline & C39 & 3 & 3 & 3 & $\ldots$ & 4 & 3 & 3 & 1 & 1 & 1 & $\ldots$ & 3 & 3 & 3 & 2 & 3 & $\ldots$ & 3 & 0 & 2 & 3 & $\ldots$ & 3 & 2 \\
\hline \multirow{5}{*}{ 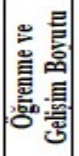 } & C40 & 3 & 3 & 2 & $\ldots$ & 1 & 2 & 4 & 4 & 2 & 3 & $\cdots$ & 3 & 3 & 3 & 3 & 3 & $\cdots$ & 2 & 2 & 0 & 1 & $\ldots$ & 2 & 1 \\
\hline & C41 & 3 & 2 & 3 & $\ldots$ & 2 & 3 & 4 & 3 & 2 & 4 & $\ldots$ & 2 & 4 & 3 & 3 & 3 & $\ldots$ & 3 & 2 & 1 & 0 & $\cdots$ & 4 & 3 \\
\hline & $\vdots$ & $\vdots$ & $\vdots$ & $\vdots$ & $\vdots$ & $\vdots$ & $\vdots$ & $\vdots$ & $\vdots$ & $\vdots$ & $\vdots$ & & $\vdots$ & $\vdots$ & $\vdots$ & $\vdots$ & $\vdots$ & & $\vdots$ & $\vdots$ & $\vdots$ & $\vdots$ & $\because$ & $\vdots$ & $\vdots$ \\
\hline & C50 & 3 & 3 & 3 & $\ldots$ & 1 & 2 & 3 & 3 & 3 & 4 & $\ldots$ & 3 & 3 & 4 & 3 & 3 & $\ldots$ & 2 & 2 & 4 & 4 & $\ldots$ & 0 & 1 \\
\hline & C51 & 3 & 3 & 4 & $\ldots$ & 3 & 4 & 4 & 3 & 4 & 4 & $\ldots$ & 3 & 4 & 4 & 3 & 3 & $\ldots$ & 3 & 3 & 2 & 2 & $\ldots$ & 2 & 0 \\
\hline
\end{tabular}


Belediyelerde Performans Ölçümü için D-ANP Temelli Bir Kurumsal Performans Kartı Uygulaması

Tablo 3. Toplam Iliş̧ki Matrisinin Elde Edilmesi

\begin{tabular}{|c|c|c|c|c|c|c|c|c|c|c|c|c|c|c|c|c|c|c|c|c|}
\hline Kriterler & $\frac{\text { C1 }}{0.0319}$ & $\frac{\mid C_{2}}{0.0396}$ & 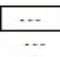 & $\frac{\text { C17 }}{0.0551}$ & $\frac{\mid \text { C18 }}{0.0422}$ & \begin{tabular}{|l|} 
C19 \\
0.0477
\end{tabular} & $\frac{\mid C_{220}}{0.0429}$ & $\cdots$ & \begin{tabular}{l|}
$\mathbf{C 2 7}$ \\
0.0608
\end{tabular} & $\frac{\mid \text { C28 }}{0.0456}$ & \begin{tabular}{|l|} 
C29 \\
0.0530
\end{tabular} & \begin{tabular}{|l|} 
C30 \\
0.0689
\end{tabular} & $\cdots$ & $\frac{\mid \mathbf{C 3 8}}{0.0279}$ & $\mid$ & \begin{tabular}{|l|} 
C40 \\
0.0438
\end{tabular} & \begin{tabular}{|l|} 
C41 \\
0.0544
\end{tabular} & - & $\frac{\mid \text { C50 }}{0.0610}$ & 0.0539 \\
\hline$C_{2}$ & 0.0463 & 0.0277 & $\cdots$ & 0.0486 & 0.0405 & 0.0301 & 0.0356 & $\cdots$ & 0.0537 & 0.0382 & 0.0513 & 0.0613 & $\cdots$ & 0.0417 & 0.0463 & 0.0418 & 0.0465 & & 0.0585 & 0.0518 \\
\hline $\begin{array}{l}\equiv \\
\mathrm{C} 17\end{array}$ & 0.0385 & 0.0412 & $\cdots$ & 0.0300 & 0.0329 & 0.0380 & 0.0383 & $\begin{array}{l}\vdots \\
\cdots\end{array}$ & 0.0505 & 0.0353 & 0.0482 & 0.0503 & $\ldots$ & 0.0294 & 0.0438 & 0.0340 & 0.0491 & $\equiv$ & 0.0505 & 0.0489 \\
\hline C18 & 0.0477 & 0.0339 & $\cdots$ & 0.0442 & 0.0318 & 0.0311 & 0.0366 & $\cdots$ & 0.0547 & 0.0446 & 0.0526 & 0.0511 & $\ldots$ & 0.0320 & 0.0424 & 0.0488 & 0.0533 & 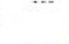 & 0.0550 & 0.0582 \\
\hline C19 & 0.0573 & 0.0434 & & 0.0489 & 0.0365 & 0.0365 & 0.0579 & & 0.0612 & 0.0613 & 0.0438 & 0.0544 & & 0.0669 & 0.0643 & 0.0541 & 0.0652 & & 0.0669 & 0.0643 \\
\hline $\mathrm{C}_{20}$ & 0.0439 & 0.0401 & & 0.0514 & 0.0490 & 0.0596 & 0.0389 & & 0.0692 & 0.0582 & 0.0418 & 0.0465 & & 0.0641 & 0.0670 & 0.0562 & 0.0673 & & 0.0641 & 0.0670 \\
\hline 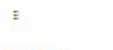 & 0.0535 & 0.0397 & & 0.0499 & 0.0481 & 0.0478 & 0.0323 & $\because$ & 0.0398 & 0.0460 & 0.0340 & 0.0491 & $=$ & 0.0614 & 0.0593 & 0.0546 & 0.0597 & $\equiv$ & 0.0614 & 0.0593 \\
\hline C27 & 0.0430 & 0.0444 & $\cdots$ & 0.0447 & 0.0376 & 0.0586 & 0.0591 & 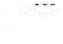 & 0.0623 & 0.0414 & 0.0488 & 0.0533 & & 0.0678 & 0.0658 & 0.0603 & 0.0660 & 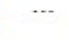 & 0.0678 & 0.0658 \\
\hline$C 28$ & 0.0474 & 0.0492 & & 0.0549 & 0.0525 & 0.0467 & 0.0527 & & 0.0562 & 0.0610 & $\overline{0541}$ & 0.0652 & & 0.0618 & 0.0649 & .0489 & 0.0653 & $=$ & 0.0618 & .0649 \\
\hline$C 29$ & 0.0479 & 0.0493 & $\cdots$ & 0.0550 & 0.0527 & 0.0529 & 0.05 & $\cdots$ & 0.0567 & 0.0620 & 562 & 0.0673 & $\cdots$ & 0.0677 & 0654 & 46 & 657 & $\cdots$ & 677 & 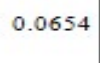 \\
\hline 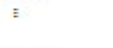 & 0.0475 & 0.0393 & ミ & 0.0493 & 0.0414 & 0.0473 & 0.0478 & $\equiv$ & 0.0601 & 0.0558 & 0.0546 & 0.0597 & & 0.0552 & 0.0590 & 0.0381 & 0.0485 & $\equiv$ & 0.0552 & 0.0590 \\
\hline $\mathrm{C} 3$ & 0.0498 & 0.0466 & $\cdots$ & 0.0522 & 0.0492 & 0.0387 & 0.0391 & $\cdots$ & 0.0579 & 0.0522 & 0.0603 & 0.0660 & $\cdots$ & 0.0580 & 0.0508 & 0.0455 & 0.0561 & 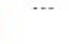 & 0.0580 & 0.0508 \\
\hline & 0.0493 & 0.0455 & & 0.0454 & 0.0542 & 0.0539 & 0.0439 & & 0.0566 & 0.0519 & 0.0349 & 0.0453 & & 0.0525 & 0.0452 & 0.0349 & 0.0453 & & 0.0525 & 0.0452 \\
\hline $\begin{array}{l}\mathrm{C} 4 \\
\mathrm{C} 4\end{array}$ & 0.0529 & 0.0437 & & 0.0546 & 0.0578 & 0.0522 & 0. & & 0.0664 & 560 & 440 & 0.0443 & & 0.0672 & 0.0599 & 440 & 0443 & 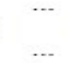 & 0.0672 & 599 \\
\hline & 0.0503 & 0.0468 & & 0.0466 & 0.0498 & 0.0497 & 0.0503 & & 0.0579 & 0.0583 & 0.0568 & 0.0620 & & 0.0427 & 0.0465 & 0.0568 & 0.0620 & & 0.0427 & 0.0465 \\
\hline C51 & 0.0575 & 0.0535 & $\cdots$ & 0.0652 & 0.0621 & 0.0568 & 0.0630 & $\cdots$ & 0.0725 & 0.0662 & 0.0538 & 0.0604 & $\cdots$ & 0.0624 & 0.0497 & 0.0538 & 0.0604 & - & 0.0624 & 0.049 \\
\hline
\end{tabular}




\subsection{DEMATEL ve ANP Yöntemleri ile Kriterlerin Ă̆ırlıklandırılması}

DEMATEL yönteminden toplam ilişki matrisi verileri elde edildikten sonra çalışmanın ANP adımları izlenerek Ağılıklandırılmamış Süpermatris (W) elde edilmiştir ve Tablo 6'da verilmiştir. Daha sonra süpermatrisin ağırlıklandırılması amacıyla, DEMATEL yönteminde kurumsal karneleme boyutları için oluşturulan toplam ilişki matrisindeki değerler kullanılarak normalizasyon işlemi gerçekleştirilip ağıllıklar elde edilmiştir. Kurumsal karneleme boyutları için hesaplanan ağırlıklar Tablo 7'de gösterilmiştir.

Tablo 7. Kurumsal Karnelemenin Boyutları İçin Ağırlıkların Hesaplanması

\begin{tabular}{|c|cccc|}
\hline Kriterler & $\begin{array}{c}\text { Finansal } \\
\text { Boyut }\end{array}$ & $\begin{array}{c}\text { Müşteri } \\
\text { Boyutu }\end{array}$ & $\begin{array}{c}\text { İç } \\
\text { Süreçler } \\
\text { Boyutu }\end{array}$ & $\begin{array}{c}\text { Öğrenme ve } \\
\text { Gelişim Boyutu }\end{array}$ \\
\hline $\begin{array}{c}\text { Finansal } \\
\text { Boyut }\end{array}$ & 0.178 & 0.346 & 0.268 & 0.208 \\
$\begin{array}{c}\text { Müşteri Boyutu } \\
\text { İç Süreçler Boyutu } \\
\text { Öğrenme ve Gelişim } \\
\text { Boyutu }\end{array}$ & 0.237 & 0.249 & 0.277 & 0.237 \\
\hline
\end{tabular}

$\mathrm{Bu}$ işlemlerin ardından ağırlıklandırılmamış süpermatrisde (W) her kriter ait olduğu boyutun ağırlığı ile çarpılarak ağırlıklandırılmış süpermatris elde edilmiştir ve Tablo 8'de gösterilmiştir. Son olarak limit süpermatris ise Tablo 9'da verilmiştir. Bu matristeki her satır değeri belediyenin performans ölçümü için elde edilen ağırlıkları temsil etmektedir. Bu sonuçlara göre 0,0302 ile C30: hizmet sonrası gelen şikâyetlerin azaltılması en yüksek ağırlığa sahip kriter olarak belirlenmiştir. Bu sonuçlara dayanarak kurumsal karneleme boyutlarından iç süreçler boyutuna daha fazla önem verildiği görülmüştür. 
Belediyelerde Performans Ölçümü için D-ANP Temelli Bir Kurumsal Performans Kartı Uygulaması

Tablo 6. Ağırlıklandırılmamış Süpermatrisin Elde Edilmesi

\begin{tabular}{|c|c|c|c|c|c|c|c|c|c|c|c|c|c|c|c|c|c|c|c|c|}
\hline Kriterler & Cl & $\mathrm{C} 2_{2}$ & $\cdots$ & $\mathrm{C} 17$ & C18 & C19 & $\mathbf{C 2 0}$ & $\cdots$ & $\mathrm{C27}$ & $\mathrm{C} 2 \mathrm{~s}$ & C29 & C30 & $\ldots$ & C38 & C39 & $\mathrm{C} 40$ & C41 & $\cdots$ & C50 & C51 \\
\hline Cl & 0.0415 & 0.0603 & $\cdots$ & 0.0546 & 0.0627 & 0.0706 & 0.0487 & $\cdots$ & 0.0712 & 0.0517 & 0.0533 & 0.0548 & $\cdots$ & 0.0643 & 0.0568 & 0.0606 & 0.0607 & & 0.0609 & 0.0556 \\
\hline $\mathrm{C}_{2}$ & 0.0516 & 0.0360 & $\cdots$ & 0.0584 & 0.0445 & 0.0534 & 0.0445 & $\ldots$ & 0.0529 & 0.0535 & 0.0552 & 0.0565 & $\ldots$ & 0.0531 & 0.0532 & 0.0559 & 0.0502 & & 0.0567 & 0.0518 \\
\hline$\vdots$ & $\vdots$ & $\vdots$ & $\because$ & : & : & : & : & $\vdots$ & $\vdots$ & ! & : & 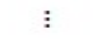 & : & : & : & & & & & \\
\hline C17 & 0.0718 & 0.0633 & $\ldots$ & 0.0425 & 0.0580 & 0.0603 & 0.0570 & $\ldots$ & 0.0665 & 0.0539 & 0.0616 & 0.0630 & $\ldots$ & 0.0667 & 0.0595 & $\begin{array}{c}\vdots \\
0.0559\end{array}$ & 0.0627 & : & $\begin{array}{c}\vdots \\
0.0564\end{array}$ & $\begin{array}{c}\vdots \\
0.0630\end{array}$ \\
\hline $\mathrm{C} 18$ & 0.0549 & 0.0527 & $\cdots$ & 0.0466 & 0.0417 & 0.0449 & 0.0543 & $\cdots$ & 0.0641 & 0.0452 & 0.0589 & 0.0604 & $\ldots$ & 0.0561 & 0.0562 & 0.0667 & 0.0664 & $\ldots$ & 0.0602 & 0.0601 \\
\hline C19 & 0.0997 & 0.0705 & & 0.0977 & 0.0747 & 0.0654 & 0.1026 & & 0.1081 & 0.1017 & 0.0869 & 0.0918 & & 0.0926 & 0.0815 & 0.1095 & 0.0944 & $\mathrm{~s}^{2}$ & 0.0936 & 0.0884 \\
\hline $\mathrm{C} 20$ & 0.0897 & 0.0835 & $\cdots$ & 0.0985 & 0.0879 & 0.1038 & 0.0670 & $\cdots$ & 0.0732 & 0.1027 & 0.0980 & 0.0929 & $\ldots$ & 0.0936 & 0.0824 & 0.0892 & 0.0860 & $\ldots$ & 0.0947 & 0.0982 \\
\hline$\vdots$ & $\begin{array}{c}\vdots \\
0.1270\end{array}$ & $\begin{array}{c}\vdots \\
0.1258\end{array}$ & & $\begin{array}{c}\vdots \\
0.1298\end{array}$ & $\begin{array}{c}\vdots \\
0.1314\end{array}$ & $\begin{array}{c}\vdots \\
0.1096\end{array}$ & $\begin{array}{c}\vdots \\
0.1191\end{array}$ & $\because$ & $\begin{array}{c}\vdots \\
0.0902\end{array}$ & $\begin{array}{c}\vdots \\
0.1082\end{array}$ & $\begin{array}{c}\vdots \\
0.1045\end{array}$ & $\begin{array}{c}\vdots \\
0.0985\end{array}$ & $\vdots$ & $\begin{array}{c}\vdots \\
0.1177\end{array}$ & $\begin{array}{c}\vdots \\
0.1219\end{array}$ & $\begin{array}{c}\vdots \\
0.1150\end{array}$ & $\begin{array}{c}\vdots \\
0.1201\end{array}$ & $\vdots$ & $\begin{array}{c}\vdots \\
0.1090\end{array}$ & $\underset{\vdots}{\vdots}$ \\
\hline $\begin{array}{l}C 27 \\
C 28\end{array}$ & 0.0953 & 0.0896 & $\begin{array}{l}\cdots \\
\ldots\end{array}$ & 0.0908 & 0.1071 & 0.1098 & 0.1002 & $\ldots$ & 0.1040 & 0.0719 & 0.1134 & 0.1075 & $\cdots$ & 0.1093 & 0.1100 & 0.1055 & 0.1013 & $\cdots$ & 0.1097 & 0.1031 \\
\hline & 0.1006 & 0.1013 & & 0.1027 & 0.1033 & 0.0878 & 0.1029 & & 0.1039 & 0.0915 & 0.0715 & 0.1085 & & 0.0986 & 0.0896 & 0.1010 & 0.0972 & & 0.0988 & 0.0949 \\
\hline C3 & 0.1309 & 0.1210 & .. & 0.1071 & 0.1005 & 0.1242 & 0.1150 & $\cdots$ & 0.1224 & 0.1116 & 0.1188 & 0.0944 & & 0.1302 & 0.1181 & 0.1209 & 0.1147 & $\cdots$ & 0.1186 & 0.1135 \\
\hline$\vdots$ & $\begin{array}{c}\vdots \\
0.0531\end{array}$ & $\begin{array}{c}\vdots \\
0.0824\end{array}$ & $\vdots$ & $\begin{array}{c}\vdots \\
0.0627\end{array}$ & $\begin{array}{c}\vdots \\
0.0628\end{array}$ & $\begin{array}{c}\vdots \\
0.0784\end{array}$ & $\begin{array}{c}\vdots \\
0.0846\end{array}$ & $\vdots$ & $\begin{array}{c}\vdots \\
0.0769\end{array}$ & $\begin{array}{c}\vdots \\
0.0830\end{array}$ & $\begin{array}{c}\vdots \\
0.0789\end{array}$ & $\begin{array}{c}\vdots \\
0.0721\end{array}$ & $\because$ & $\begin{array}{c}\vdots \\
0.0515\end{array}$ & $\begin{array}{c}\vdots \\
0.0802\end{array}$ & $\begin{array}{c}\vdots \\
0.0718\end{array}$ & $\begin{array}{c}\vdots \\
0.0786\end{array}$ & $\vdots$ & $\begin{array}{c}\vdots \\
0.0713\end{array}$ & $\begin{array}{c}\vdots \\
0.0764\end{array}$ \\
\hline $\begin{array}{r}\mathrm{C} 30 \\
\mathrm{C}\end{array}$ & 0.0908 & 0.0915 & $\ldots$ & 0.0933 & 0.0835 & 0.0861 & 0.0848 & . & 0.0759 & 0.0820 & 0.0882 & 0.0801 & 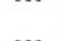 & 0.0888 & 0.0607 & 0.0814 & 0.0788 & 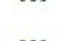 & 0.0796 & 0.0852 \\
\hline & 0.0817 & 0.0844 & & 0.0454 & 0.0542 & 0.0816 & 0.0837 & & 0.0944 & 0.0915 & 0.0759 & 0.0833 & & 0.0762 & \begin{tabular}{|c|}
0.0827 \\
\end{tabular} & 0.0615 & 0.0686 & & 0.1012 & 0.0811 \\
\hline C41 & 0.1013 & 0.0940 & .. & 0.0546 & 0.0578 & 0.0984 & 0.1003 & . & 0.1033 & 0.1002 & 0.1013 & 0.1003 & 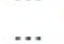 & 0.0972 & 0.1021 & 0.0798 & 0.0691 & $\ldots$ & 0.1104 & 0.0910 \\
\hline $\begin{array}{l}\vdots \\
c 5\end{array}$ & $\begin{array}{c}\vdots \\
0.1136\end{array}$ & $\begin{array}{c}\vdots \\
0.1182\end{array}$ & $\vdots$ & $\begin{array}{c}\vdots \\
0.1118\end{array}$ & $\begin{array}{c}\vdots \\
0.0917\end{array}$ & $\begin{array}{c}\vdots \\
0.1010\end{array}$ & $\begin{array}{c}\vdots \\
0.0956\end{array}$ & & $\begin{array}{c}\vdots \\
0.1061\end{array}$ & $\begin{array}{c}\vdots \\
0.1030\end{array}$ & $\begin{array}{c}\vdots \\
0.0960\end{array}$ & $\begin{array}{c}\vdots \\
0.1033\end{array}$ & & $\begin{array}{c}\vdots \\
0.1106\end{array}$ & $\begin{array}{c}\vdots \\
0.1054\end{array}$ & $\begin{array}{c}\vdots \\
0.0924\end{array}$ & $\begin{array}{c}\vdots \\
0.1049\end{array}$ & $\therefore$ & $\begin{array}{c}\vdots \\
0.0760\end{array}$ & $\begin{array}{c}\vdots \\
0.0941\end{array}$ \\
\hline 51 & 0.1005 & 0.1047 & 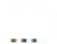 & 0.1083 & 0.0970 & 0.0971 & 0.0998 & $\ldots$ & 0.1026 & 0.0999 & 0.1007 & 0.0998 & & 0.1181 & 0.0924 & 0.0795 & 0.0934 & $\ldots$ & 0.0828 & 0.0749 \\
\hline
\end{tabular}


Burak ERKAYMAN - Mustafa Engin KOCADA ĞISTAN - Özge ALBAYRAK

Tablo 7. Ağırlıklandırılmış Süpermatrisin Elde Edilmesi

\begin{tabular}{|c|c|c|c|c|c|c|c|c|c|c|c|c|c|c|c|c|c|c|c|c|}
\hline \begin{tabular}{|l|} 
Kriterler \\
$C 1$
\end{tabular} & 10 & $\begin{array}{l}\text { C2 } \\
0.0129\end{array}$ & $\begin{array}{l}\ldots \\
\cdots\end{array}$ & \begin{tabular}{|l|} 
C17 \\
0.0117
\end{tabular} & $\begin{array}{l}\text { C18 } \\
0.0135\end{array}$ & 19 & $\begin{array}{l}\text { C20 } \\
0.0135\end{array}$ & $\begin{array}{l}\cdots \\
\cdots\end{array}$ & $\begin{array}{l}C 27 \\
.0198\end{array}$ & $\begin{array}{l}\text { C28 } \\
0.0144\end{array}$ & 29 & C30 & $\begin{array}{ll}\cdots \\
\cdots\end{array}$ & $\begin{array}{l}\text { C38 } \\
0.0177\end{array}$ & C39 & C40 & C41 & $\cdots$ & $\begin{array}{l}\text { C50 } \\
0.0140\end{array}$ & C51 \\
\hline Cl & 889 & & 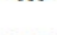 & & 0.0135 & 0.0196 & 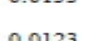 & $\cdots$ & & 0 & & 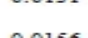 & $\cdots$ & 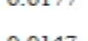 & & 39 & 39 & & & 28 \\
\hline $\mathrm{C} 2$ & 0.0111 & 0.0077 & $\cdots$ & 0.0125 & 0.0096 & 0.0148 & 0.0123 & $\cdots$ & 0.0147 & 0.0148 & 0.0152 & 0.0156 & $\cdots$ & 0.0147 & 0.0147 & 0.0128 & 0.0115 &.. & 0.0130 & 0.0119 \\
\hline$\vdots$ & $\vdots$ & $\vdots$ & $\because$ & $\vdots$ & $\vdots$ & $\vdots$ & $\vdots$ & $\vdots$ & $\vdots$ & $\vdots$ & : & $\vdots$ & : & $\vdots$ & $\vdots$ & & & : & & \\
\hline $\mathrm{Cl} 17$ & 0.0154 & 0.0136 & $\ldots$ & 0.0091 & 0.0125 & 0.0167 & 0.0158 & $\cdots$ & 0.0184 & 0.0149 & 0.0170 & 0.0174 & $\ldots$ & 0.0184 & 0.0164 & 0.0128 & 0.0144 & 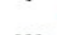 & 0.0130 & 0.0145 \\
\hline $\mathrm{C} 18$ & 0.0118 & 0.0113 & $\ldots$ & 0.0100 & 0.0090 & 0.0125 & 0.0151 & $\cdots$ & 0.0178 & 0.0126 & 0.0163 & 0.0167 & $\ldots$ & 0.0155 & 0.0155 & 0.0153 & 0.0152 & & 0.0138 & 0.0138 \\
\hline C19 & 0.0285 & 0.0202 & $\ldots$ & 0.0279 & 0.0214 & 0.0131 & 0.0205 & & 0.0216 & 0.0203 & 0.0248 & 0.0262 & 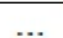 & 0.0264 & 0.0232 & 0.0287 & 0.0247 & 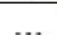 & 0.0245 & 0.0231 \\
\hline $\mathrm{C} 20$ & 0.0256 & 0.0239 & 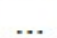 & 0.0282 & 0.0251 & 0.0207 & 0.0134 & 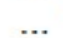 & 0.0146 & 0.0205 & 0.0279 & 0.0265 & 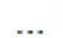 & 0.0267 & 0.0235 & 0.0233 & 0.0225 & 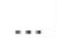 & 0.0248 & 0.0257 \\
\hline$\vdots$ & $\begin{array}{c}\vdots \\
0.0363\end{array}$ & $\begin{array}{c}\vdots \\
0.0360\end{array}$ & & $\begin{array}{c}\vdots \\
0.0371\end{array}$ & $\begin{array}{c}\vdots \\
0.0376\end{array}$ & $\begin{array}{c}\vdots \\
0.0219\end{array}$ & $\begin{array}{c}\vdots \\
0.0238\end{array}$ & $\because$ & $\begin{array}{c}\vdots \\
0.0180\end{array}$ & $\begin{array}{c}\vdots \\
0.0216\end{array}$ & $\begin{array}{c}\vdots \\
0.0298\end{array}$ & $\begin{array}{c}\vdots \\
0.0281\end{array}$ & $\vdots$ & $\begin{array}{c}\vdots \\
0.0336\end{array}$ & $\begin{array}{c}\vdots \\
0.0348\end{array}$ & $\begin{array}{c}\vdots \\
0.0301\end{array}$ & $\begin{array}{c}\vdots \\
0.0314\end{array}$ & $\vdots$ & $\begin{array}{c}\vdots \\
0.0285\end{array}$ & $\begin{array}{c}\vdots \\
0.0295\end{array}$ \\
\hline $2 \pi$ & 0.0273 & 0.0256 & & 0.0260 & 0.0306 & 0.0219 & 0.0200 & & 0.0208 & 0.0144 & 0.0323 & 0.0306 & & 0.0312 & 0.0314 & 0.0276 & 0.0265 & & 0.0287 & 0.0270 \\
\hline 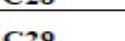 & 0.0251 & 0.0253 & $\ldots$ & 0.0256 & 0.0258 & 0.0230 & 0.0269 & $\cdots$ & 0.0272 & 0.0239 & 0.0157 & 0.0238 & $\ldots$ & 0.0217 & 0.0197 & 0.0257 & 0.0247 & 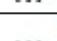 & 0.0251 & 0.0241 \\
\hline C30 & 0.0327 & 0.0302 & $\ldots$ & 0.0267 & 0.0251 & 0.0325 & 0.0301 & 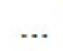 & 0.0320 & 0.0292 & 0.0261 & 0.0207 & & 0.0286 & 0.0259 & 0.0308 & 0.0292 & 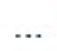 & 0.0302 & 0.0289 \\
\hline$\vdots$ & $\begin{array}{c}\vdots \\
0.0132\end{array}$ & $\begin{array}{c}\vdots \\
0.0206\end{array}$ & $\vdots$ & $\begin{array}{c}\vdots \\
0.0156\end{array}$ & $\begin{array}{c}\vdots \\
0.0157\end{array}$ & $\begin{array}{c}\vdots \\
0.0205\end{array}$ & $\begin{array}{c}\vdots \\
0.0221\end{array}$ & $\vdots$ & $\begin{array}{c}\vdots \\
0.0201\end{array}$ & $\begin{array}{c}\vdots \\
0.0217\end{array}$ & $\begin{array}{c}\vdots \\
0.0173\end{array}$ & $\begin{array}{c}\vdots \\
0.0158\end{array}$ & $\because$ & $\begin{array}{c}\vdots \\
0.0113\end{array}$ & 0.0176 & $\begin{array}{c}\vdots \\
0.0183\end{array}$ & $\begin{array}{c}\vdots \\
0.0200\end{array}$ & $\vdots$ & $\begin{array}{c}\vdots \\
0.0181\end{array}$ & $\begin{array}{c}\vdots \\
0.0194\end{array}$ \\
\hline C39 & 0.0227 & 0.0228 & 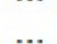 & 0.0233 & 0.0208 & 0.0225 & 0.0222 & $\ldots$ & 0.0198 & 0.0214 & 0.0194 & 0.0176 & $\ldots$ & 0.0195 & 0.0133 & 0.0207 & 0.0200 & 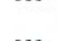 & 0.0202 & 0.0217 \\
\hline & 0.0204 & 0.0211 & & 0.0188 & 0.0203 & 0.0213 & 0.0219 & & 0.0247 & 0.0239 & 0.0167 & 0.0183 & & 0.0167 & 0.0182 & 0.0156 & 0.0175 & & 0.0257 & 0.0206 \\
\hline 40 & 0.0253 & 0.0235 & . & 0.0271 & 0.0222 & 0.0257 & 0.0262 & $\cdots$ & 0.0270 & 0.0262 & 0.0222 & 0.0220 & $\cdots$ & 0.0213 & 0.0224 & 0.0203 & 0.0176 & . & 0.0281 & 0.0231 \\
\hline$\vdots$ & $\begin{array}{c}\vdots \\
\vdots \\
0.0284\end{array}$ & $\begin{array}{c}\vdots \\
0.0295\end{array}$ & $\vdots$ & $\begin{array}{c}\vdots \\
0.0279\end{array}$ & $\begin{array}{c}\vdots \\
0.0229\end{array}$ & $\begin{array}{c}\vdots \\
0.0264\end{array}$ & $\begin{array}{c}\vdots \\
0.0250\end{array}$ & & $\begin{array}{c}\vdots \\
0.0277\end{array}$ & $\begin{array}{c}\vdots \\
0.0269\end{array}$ & $\begin{array}{c}\vdots \\
\vdots \\
0.0211\end{array}$ & $\begin{array}{c}\vdots \\
0.0227\end{array}$ & & $\begin{array}{c}\vdots \\
0.0243\end{array}$ & $\begin{array}{c}\vdots \\
\vdots \\
0.0231\end{array}$ & $\begin{array}{c}\vdots \\
0.0235\end{array}$ & $\begin{array}{c}\vdots \\
0.0267\end{array}$ & $\because$ & $\begin{array}{c}\vdots \\
0.0193\end{array}$ & $\begin{array}{c}\vdots \\
\vdots \\
0.0239\end{array}$ \\
\hline C51 & 0.0251 & 0.0261 & $\ldots$ & 0.0270 & 0.0242 & 0.0254 & 0.0261 & $\cdots$ & 0.0268 & 0.0261 & 0.0221 & 0.0219 & $\cdots$ & 0.0259 & 0.0203 & 0.0202 & 0.0238 & $\cdots$ & 0.0211 & 0.0191 \\
\hline
\end{tabular}


Belediyelerde Performans Ölçümü için D-ANP Temelli Bir Kurumsal Performans Kartı Uygulaması

Tablo 8. Limit Süpermatrisin Elde Edilmesi

\begin{tabular}{|c|c|c|c|c|c|c|c|c|c|c|c|c|c|c|c|c|c|c|c|c|}
\hline Kriterler & 1 & $\mathrm{C2}$ & $\cdots$ & $\mathrm{Cl7}$ & 18 & 19 & C20 & $\cdots$ & C27 & C28 & C29 & \begin{tabular}{|l|} 
C30 \\
\end{tabular} & $\cdots$ & C38 & C39 & C40 & C41 & $\cdots$ & C50 & \begin{tabular}{|l|} 
C51 \\
0.0146
\end{tabular} \\
\hline $\mathrm{Cl}$ & 6146 & 0146 & $\cdots$ & 0.0146 & 0146 & 6146 & 0.0146 & $\cdots$ & 0.0146 & 0.0146 & 0146 & 0.0146 & $\cdots$ & 0.0146 & 0.0146 & 0.0146 & 0.0146 & & 0.0146 & 0.0146 \\
\hline $\mathrm{C} 2$ & 0.0131 & 0.0131 & $\cdots$ & 0.0131 & 0.0131 & 0.0131 & 0.0131 & $\cdots$ & 0.0131 & 0.0131 & 0.0131 & 0.0131 & $\ldots$ & 0.0131 & 0.0131 & 0.0131 & 0.0131 &. & 0.0131 & 0.0131 \\
\hline$\vdots$ & $\vdots$ & $\vdots$ & $\because$ & $\vdots$ & $\vdots$ & $\vdots$ & $\vdots$ & $\vdots$ & $\vdots$ & $\vdots$ & $\vdots$ & $\vdots$ & $\vdots$ & $\vdots$ & $\vdots$ & & & & & \\
\hline $\mathrm{Cl7}$ & 0.0152 & 0.0152 & $\cdots$ & 0.0152 & 0.0152 & 0.0152 & 0.0152 & $\ldots$ & 0.0152 & 0.0152 & 0.0152 & 0.0152 & $\ldots$ & 0.0152 & 0.0152 & 0.0152 & 0.0152 & 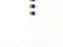 & $\begin{array}{c}\vdots \\
0.0152\end{array}$ & $\begin{array}{c}\vdots \\
0.0152\end{array}$ \\
\hline $\mathrm{Cls}$ & 0.0144 & 0.0144 & $\cdots$ & 0.0144 & 0.0144 & 0.0144 & 0.0144 & $\cdots$ & 0.0144 & 0.0144 & 0.0144 & 0.0144 & $\cdots$ & 0.0144 & 0.0144 & 0.0144 & 0.0144 & $\cdots$ & 0.0144 & 0.0144 \\
\hline C19 & 0.0237 & 0.0237 & & 0.0237 & 0.0237 & 0.0237 & 0.0237 & $\cdots$ & 0.0237 & 0.0237 & 0.0237 & 0.0237 & & 0.0237 & 0.0237 & 0.0237 & 0.0237 & $\ldots$ & 0.0237 & 0.0237 \\
\hline $\mathrm{C} 20$ & 0.0239 & 0.0239 & 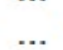 & 0.0239 & 0.0239 & 0.0239 & 0.0239 & 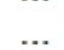 & 0.0239 & 0.0239 & 0.0239 & 0.0239 & 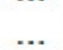 & 0.0239 & 0.0239 & 0.0239 & 0.0239 & 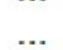 & 0.0239 & 0.0239 \\
\hline$\vdots$ & $\begin{array}{c}\vdots \\
0.0295\end{array}$ & $\begin{array}{c}\vdots \\
0.0295\end{array}$ & & $\begin{array}{c}\vdots \\
0.0295\end{array}$ & $\begin{array}{c}\vdots \\
0.0295\end{array}$ & $\begin{array}{c}\vdots \\
0.0295\end{array}$ & $\begin{array}{c}\vdots \\
0.0295\end{array}$ & $\because$ & $\begin{array}{c}\vdots \\
0.0295\end{array}$ & $\begin{array}{c}\vdots \\
0.0295\end{array}$ & $\begin{array}{c}\vdots \\
0.0295\end{array}$ & $\begin{array}{c}\vdots \\
0.0295\end{array}$ & $\vdots$ & $\begin{array}{c}\vdots \\
0.0295\end{array}$ & $\begin{array}{c}\vdots \\
0.0295\end{array}$ & $\begin{array}{c}\vdots \\
0.0295\end{array}$ & $\begin{array}{c}\vdots \\
0.0295\end{array}$ & : & $\begin{array}{c}\vdots \\
0.0295\end{array}$ & $\begin{array}{c}\vdots \\
0.0295\end{array}$ \\
\hline $\begin{array}{l}\mathrm{C} 2 \mathrm{C} \\
\mathrm{C} 2 \mathrm{~s}\end{array}$ & 0.0260 & 0.0260 & $\begin{array}{l}\cdots \\
\ldots \\
\end{array}$ & 0.0260 & 0.0260 & 0.0260 & 0.0260 & $\cdots$ & 0.0260 & 0.0260 & 0.0260 & 0.0260 & 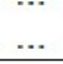 & 0.0260 & 0.0260 & 0.0260 & 0.0260 & $\ldots$ & 0.0260 & 0.0260 \\
\hline $\begin{array}{l}C 29 \\
C 30\end{array}$ & $\begin{array}{l}0.0240 \\
0.0302\end{array}$ & $\begin{array}{l}0.0240 \\
0.0302\end{array}$ & $\begin{array}{l}\ldots \\
\ldots\end{array}$ & $\begin{array}{l}0.0240 \\
0.0302\end{array}$ & $\begin{array}{l}0.0240 \\
0.0302\end{array}$ & $\begin{array}{l}0.0240 \\
0.0302\end{array}$ & $\begin{array}{l}0.0240 \\
0.0302\end{array}$ & & $\begin{array}{l}0.0240 \\
0.0302\end{array}$ & $\begin{array}{l}0.0240 \\
0.0302\end{array}$ & $\begin{array}{l}0.0240 \\
0.0302\end{array}$ & $\begin{array}{l}0.0240 \\
0.0302\end{array}$ & 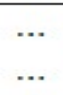 & $\begin{array}{l}0.0240 \\
0.0302\end{array}$ & $\begin{array}{l}0.0240 \\
0.0302\end{array}$ & $\begin{array}{l}0.0240 \\
0.0302\end{array}$ & $\begin{array}{l}0.0240 \\
0.0302\end{array}$ & $\ldots$ & $\begin{array}{l}0.0240 \\
0.0302\end{array}$ & $\begin{array}{l}0.0240 \\
0.0302\end{array}$ \\
\hline $\begin{array}{l}\vdots \\
\text { C38 }\end{array}$ & 0.0178 & $\begin{array}{c}\vdots \\
0.0178\end{array}$ & $\vdots$ & $\begin{array}{c}\vdots \\
0.0178\end{array}$ & $\begin{array}{c}\vdots \\
0.0178\end{array}$ & $\begin{array}{c}\vdots \\
0.0178\end{array}$ & $\begin{array}{c}\vdots \\
0.0178\end{array}$ & $\vdots$ & $\begin{array}{c}\vdots \\
0.0178\end{array}$ & $\begin{array}{c}\vdots \\
0.0178\end{array}$ & $\begin{array}{c}\vdots \\
0.0178\end{array}$ & $\begin{array}{c}\vdots \\
0.0178\end{array}$ & $\because$ & $\begin{array}{c}\vdots \\
0.0178\end{array}$ & $\begin{array}{c}\vdots \\
0.0178\end{array}$ & $\begin{array}{c}\vdots \\
0.0178\end{array}$ & $\begin{array}{c}\vdots \\
0.0178\end{array}$ & $\vdots$ & $\begin{array}{c}\vdots \\
0.0178\end{array}$ & $\begin{array}{c}\vdots \\
0.0178\end{array}$ \\
\hline C39 & 0.0205 & 0.0205 & $\ldots$ & 0.0205 & 0.0205 & 0.0205 & 0.0205 & $\ldots$ & 0.0205 & 0.0205 & 0.0205 & 0.0205 & $\ldots$ & 0.0205 & 0.0205 & 0.0205 & 0.0205 & $\ldots$ & 0.0205 & 0.0205 \\
\hline $\mathrm{C} 40$ & 0.0211 & 0.0211 & & 0.0211 & 0.0211 & 0.0211 & 0.0211 & & 0.0211 & 0.0211 & 0.0211 & 0.0211 & & 0.0211 & 0.0211 & 0.0211 & 0.0211 & & 0.0211 & 0.0211 \\
\hline $\mathrm{C} 41$ & 0.0242 & 0.0242 & $\ldots$ & 0.0242 & 0.0242 & 0.0242 & 0.0242 & 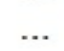 & 0.0242 & 0.0242 & 0.0242 & 0.0242 & & 0.0242 & 0.0242 & 0.0242 & 0.0242 & $\ldots$ & 0.0242 & 0.0242 \\
\hline $\begin{array}{l}\vdots \\
\text { C50 }\end{array}$ & $\begin{array}{c}\vdots \\
0.0252\end{array}$ & $\begin{array}{c}\vdots \\
0.0252\end{array}$ & $\begin{array}{c}\vdots \\
\ldots\end{array}$ & $\begin{array}{c}\vdots \\
0.0252\end{array}$ & $\begin{array}{c}\vdots \\
0.0252\end{array}$ & $\begin{array}{c}\vdots \\
0.0252\end{array}$ & $\begin{array}{c}\vdots \\
0.0252\end{array}$ & $\cdots$ & $\begin{array}{c}\vdots \\
0.0252\end{array}$ & $\begin{array}{c}\vdots \\
0.0252\end{array}$ & $\begin{array}{c}\vdots \\
0.0252\end{array}$ & $\begin{array}{c}\vdots \\
0.0252\end{array}$ & $\cdots$ & $\begin{array}{c}\vdots \\
0.0252\end{array}$ & $\begin{array}{c}\vdots \\
0.0252\end{array}$ & $\begin{array}{c}\vdots \\
0.0252\end{array}$ & $\begin{array}{c}\vdots \\
0.0252\end{array}$ & $\begin{array}{l}\ddots \\
\ldots\end{array}$ & $\begin{array}{c}\vdots \\
0.0252\end{array}$ & $\begin{array}{c}\vdots \\
0.0252\end{array}$ \\
\hline C51 & 0.0241 & 0.0241 & $\ldots$ & 0.0241 & 0.0241 & 0.0241 & 0.0241 & $\cdots$ & 0.0241 & 0.0241 & 0.0241 & 0.0241 & $\ldots$ & 0.0241 & 0.0241 & 0.0241 & 0.0241 & $\cdots$ & 0.0241 & 0.0241 \\
\hline
\end{tabular}




\section{Sonuç}

Yerel yönetimlerdeki hizmet politikası kanunların yanında siyasal tabanlara da dayalı yürütülmektedir. Bu konuda performans yönetimi ve değerlendirmesinin \%100 ile sonuçlanması oldukça zordur. Çünkü sistemin tam işleyememesinin nedenlerinin başında her seçim döneminde değişen başkanlık ve yönetimi ile belirli dönemlerden fazla yöneticilik yapılamaması gerçeği gelmektedir. Çalışan personelin sabit kaldığı fakat yöneticilerinin en az 5 en fazla 10 yılda bir değişiyor olması, özellikle personellerde motivasyon kaybına neden olmaktadır. Bu açıdan performans değerlendirme ve ölçme yapılması anketlerle de desteklenmedir. Bu bakımdan verilen hizmetin eşit olarak sunumu önemlidir. $\mathrm{Bu}$ durumda verilen hizmetin kalitesi büyük oranda anket sonuçları ile elde edilecektir. Çünkü yerel yönetimlerde verilen hizmetin bir sınırının olmaması, işi oldukça zor bir hale sokmakta ve gerekli standartları yakalamak güçleşmektedir. Verilen hizmetin toplumun her kesimine ve farklı siyasi görüşlere sahip vatandaşlara çözüm odaklı yansıtılmış olması başarıyı getirecektir. Performans yönetiminin doğru planlanması ve uygulanması bu sonuçlara ulaşılmakta son derece önemlidir. Yerel yönetimlerde performans yönetim sistemi iyi bir şekilde uygulanmışsa, hizmet veren tüm personelin yaptıkları işi ve verdikleri hizmeti hangi amaca yönelik yaptıkları, ne tür önceliklerin olduğu, teknoloji ile paralellik gibi birçok konuda bilinçlendirilmiş olacağ 1 , memnuniyetle sonuçlanan hizmet sonrasında gerekli ödüllendirme, kariyer gelişimi gibi pozitif etkilerinin olacağı bir gerçektir. Kısacası performans yönetimi sonucunda personel her konuda bilinçlendirilmiş olacaktır ve bunun anketlere yansıması da yönetimler lehine oluşacaktır. Performans uygulamaları sayesinde verilen hizmetin sonuçlarının memnuniyet verici ve hızlı bir şekilde sonuçlandırılması, bütçe performansının ve hizmet kalitesinin artışına etki edecektir.

$\mathrm{Bu}$ çalışmada, bir ilimizdeki belediyenin performansını değerlendirmek için kurumsal karnelemenin dört boyutu ele alınarak hibrit çok kriterli karar verme yöntemi DEMATEL-ANP (D-ANP) kullanılmıştır. D-ANP yöntemi ile belediyenin performans yönetimindeki en önemli özelliğin C30: hizmet sonrası gelen şikâyetlerin azaltılması olduğu bulunmuştur. Kurumsal Karneleme boyutları açısından bakıldığında ise iç süreçler boyutunun daha fazla öneme sahip olduğu görülmüş ve müşteri boyutu da onu takip etmektedir.

Gelecek çalışmalarda çok kriterli karar verme tekniklerinin farklı kombinasyonları kullanılabilir. Ayrıca bu çalışmada kullanılan yöntemler dışında bulanık karar verme tekniklerinden de istifade edilebilir. Her yönüyle zor bir problem olan performans değerlendirmede yeni boyutlar eklenip sonuçları takip edilebilir.

\section{Kaynaklar}

Abikova, J. (2020). Application of fuzzy DEMATEL-ANP methods for siting refugee camps. Journal of Humanitarian Logistics and Supply Chain Management. 
Belediyelerde Performans Ölçümü için D-ANP Temelli Bir Kurumsal Performans Kartı Uygulamast

Agrawal, S., Singh, R. K., \& Murtaza, Q. (2016). Outsourcing decisions in reverse logistics: Sustainable balanced scorecard and graph theoretic approach. Resources, Conservation and Recycling, 108, 41-53.

Akçakaya, M. (2017). Yerel Yönetimlerde Performans Yönetimi ve Karsilasilan Sorunlar/Performance Management and Problems in Local Administrations. Third Sector Social Economic Review, 52(1), 56.

Albayrak, Ö., \& Erkayman, B. (2018). Bulanik DEMATEL ve EDAS Yöntemleri Kullanilarak Sporcular İçin Akilli Bileklik Seçimi. Ergonomi, 1(2), 92102.

Aujirapongpan, S., Meesook, K., Theinsathid, P., \& Maneechot, C. (2020). Performance Evaluation of Community Hospitals in Thailand: An Analysis Based on the Balanced Scorecard Concept. Iranian Journal of Public Health, 49(5), 906-913.

Dağdeviren, M., \& Yüksel, İ. (2007). Personnel selection using analytic network process.

Demirel, D. (2018). Rethinking Performance Management Practices in Local Administrations? An Evaluation of BV, CPA, And WPI Practices in the United Kingdom. Foundations of Management, 10(1), 87-98.

Erbaşi, A. Balanced scorecard performans değerlendirme yönteminin Türkçe yazındaki tercüme problemi. Verimlilik Dergisi, 2012(2), 61-86.

Frederico, G. F., Garza-Reyes, J. A., Kumar, A., \& Kumar, V. (2020). Performance measurement for supply chains in the Industry 4.0 era: a balanced scorecard approach. International Journal of Productivity and Performance Management.

Gencer, C., \& Çetin, T. (2011). Kurumsal performans karnesi ve havacilık sektöründe bir uygulama. Savunma Bilimleri Dergisi, 10(2), 105-121.

Gök, A. C., \& Perçin, S. (2016). Elektronik Alışveriş (E-alışveriş) Sitelerinin Ehizmet Kalitesi Açısından Değerlendirilmesinde DEMATEL-AASVIKOR Yaklaşımı. Anadolu Üniversitesi Sosyal Bilimler Dergisi, 16(2), 131-144.

Günay, B., \& Kaya, İ. (2017). Borsa İstanbul'da Yer Alan Aracı Kurumların Performansının Çok Kriterli Karar Verme Yöntemleri İle Değerlendirilmesi. Celal Bayar University Journal of Social Sciences/Celal Bayar Üniversitesi Sosyal Bilimler Dergisi, 15(2).

Güner, M. F., \& Memış, M. Ü. (2007). Kurumsal Performans Değerlendirme Yöntemlerinin Gelişim Süreci: 1850'lerden 2000'lere Bir İnceleme. Journal of the Cukurova University Institute of Social Sciences, 16(2).

Hsu, C.-H., Wang, F.-K., \& Tzeng, G.-H. (2012). The best vendor selection for conducting the recycled material based on a hybrid MCDM model combining DANP with VIKOR. Resources, Conservation and Recycling, 66, 95-111.

Kaplan, R., \& Norton, D. a.(1992). The Balanced Scorecard-Measures that Drive Performance. Harvard Business Review, 71-79. 
Kaplan, R. S., \& Norton, D. P. (1996). Linking the balanced scorecard to strategy. California management review, 39(1), 53-79.

Karasoy, H. A. (2014). Türk kamu yönetiminde performans yönetimine bir bakış. Uluslararası Yönetim İktisat ve İsletme Dergisi, 10(22), 257-274.

Köseoğlu, Ö. (2005). Belediyelerde performans yönetimi. Türk İdare Dergisi, 447, 211-234.

Liu, P. C., Lo, H.-W., \& Liou, J. J. (2020). A Combination of DEMATEL and BWM-Based ANP Methods for Exploring the Green Building Rating System in Taiwan. Sustainability, 12(8), 3216.

Lu, M.-T., Hsu, C.-C., Liou, J. J., \& Lo, H.-W. (2018). A hybrid MCDM and sustainability-balanced scorecard model to establish sustainable performance evaluation for international airports. Journal of Air Transport Management, 71, 9-19.

Ocampo, L., Deiparine, C. B., \& Go, A. L. (2020). Mapping Strategy to Best Practices for Sustainable Food Manufacturing Using Fuzzy DEMATELANP-TOPSIS. Engineering Management Journal, 1-21.

Okutan, E., \& Y1lmaz, B. (2019). Kamuda Performans Yönetimi ve Performans Değerlemesinin Yansıması: Mersin Büyükşehir Belediyesi Örneği. Bilgi, 21(2).

Övgün, B., Özkal Sayan, İ., \& Zengin, O. (2018). Türk Kamu Yönetiminde Performans Değerlendirmesi Ve Denetimi Mümkün Mü?

Puente, J., Fernandez, I., Gomez, A., \& Priore, P. (2020). Integrating Sustainability in the Quality Assessment of EHEA Institutions: A Hybrid FDEMATEL-ANP-FIS Model. Sustainability, 12(5), 1707.

Saaty, T. L., \& Vargas, L. G. (2006). Decision making with the analytic network process (Vol. 282): Springer.

Sarıaltın, H. (2017). Performans yönetiminde performans değerlendirme ve öneri sitemlerinin sürdürülebilir verimliliğe etkisinin incelenmesi: Bir örnek olay çalışması. İşletme Bilimi Dergisi, 5(1), 117-141.

Sarraf, F., \& Nejad, S. H. (2020). Improving performance evaluation based on balanced scorecard with grey relational analysis and data envelopment analysis approaches: Case study in water and wastewater companies. Evaluation and Program Planning, 79, 101762.

St-Hilaire, W. A. (2020). Key-synergies between strategic resources and operational tool orchestration for organization development. Journal of Management Development.

Tzeng, G.H., Chiang, C.H., \& Li, C.W. (2007). Evaluating intertwined effects in e-learning programs: A novel hybrid MCDM model based on factor analysis and DEMATEL. Expert systems with Applications, 32(4), 10281044.

Yılmaz, G. (2018). Kurumsal Sürdürülebilirlik Ölçümünde Dengeli Performans Karnesi Yaklaşımı Ve Bir Model Önerisi: TOPSIS Yöntemi Ile Şirketlerin Değerlendirilmesi. 